\title{
Neurosyphilis with Mesiotemporal Magnetic Resonance Imaging Abnormalities
}

\author{
Kiwa Hama ${ }^{1}$, Hiroshi Ishiguchi ${ }^{1}$, Tomikimi Tuji ${ }^{2}$, Hideto Miwa ${ }^{1}$ and Tomoyoshi Kondo ${ }^{1}$
}

\begin{abstract}
We describe a patient with mesial temporal T2-weighted image hyperintensity on magnetic resonance imaging that mimicked paraneoplastic limbic encephalitis. The patient showed pupillary abnormalities suggestive of a diagnosis of neurosyphilis, and the diagnosis was supported by the results of a serum Treponema pallidum hemagglutination assay (TPHA) and cerebrospinal fluid examination. Making a diagnosis of neurosyphilis is occasionally difficult because of the variety of clinical and imaging findings. Appropriate diagnosis and commencing adequate treatment are needed for a good prognosis; thus, neurosyphilis should be included in the differential diagnosis of mesiotemporal magnetic resonance imaging abnormalities.
\end{abstract}

Key words: neurosyphilis, mesiotemporal region, limbic structure, paraneoplastic limbic encephalitis, herpes simplex encephalopathy, magnetic resonance imaging

(Inter Med 47: 1813-1817, 2008)

(DOI: 10.2169/internalmedicine.47.0983)

\section{Introduction}

Neurosyphilis has a wide variety of central nervous system manifestations, either clinically or neuroradiologically, occasionally making an appropriate diagnosis difficult. The range of manifestations includes normal results of magnetic resonance (MR) and computed tomography (CT) imaging procedures, mild to moderate atrophy, cerebral infarction, white matter lesions, cerebral gummas, leptomeningeal enhancement, and arteritis (1). Recently, we encountered a patient with neurosyphilis who showed mesial temporal T2weighted image (T2WI) hyperintensity on MR imaging (MRI) that mimicked paraneoplastic limbic encephalitis. The characteristic pupillary abnormality of this patient led us to make a diagnosis of neurosyphilis.

\section{Case Report}

A 51-year-old man was admitted to our hospital because of a 12-month history of impairment of intellect and memory, and personality changes. There was no history of trauma, headaches, fever, nausea, seizure, use of illicit drugs, or alcohol abuse. He denied a high rate of sex partners, either homosexual or heterosexual. On admission, his general condition was unremarkable. There were no skin lesions or palpable lymph nodes. On neurological examination he was alert, but he showed marked disorientation and cognitive impairment with a Mini-Mental State Examination score (MMSE) of 0/30. He was cooperative, but displayed a slightly euphoric mood. His speech was non-fluent, but his understanding of the simple order and repetition of words was fairly good. There was no visual defect. His pupils were approximately $6 \mathrm{~mm}$ in diameter bilaterally, and were unreactive to light and accommodation, with no constriction, even following prolonged near effort. The pupils constricted with pilocarpine. There was no limitation of extraocular muscles. The other cranial nerves were intact. There was no sensory or motor paresis in his limbs or body. The deep tendon reflexes were mildly brisk, and plantar responses were flexor. Intermittent myoclonus was present in the right upper and lower extremities. There was no cerebellar ataxia in his extremities, but his gait was mildly unstable due to the myoclonus. There were no signs of meningeal irritation.

The results of routine laboratory tests were normal, except for some abnormalities in his serological tests for syphilis,

${ }^{1}$ Department of Neurology, Wakayama Medical University, Wakayama and ${ }^{2}$ Department of Psychiatry, Wakayama Medical University, Wakayama

Received for publication February 3, 2008; Accepted for publication June 17, 2008

Correspondence to Dr. Kiwa Hama, kiwasuga@wakayama-med.ac.jp 


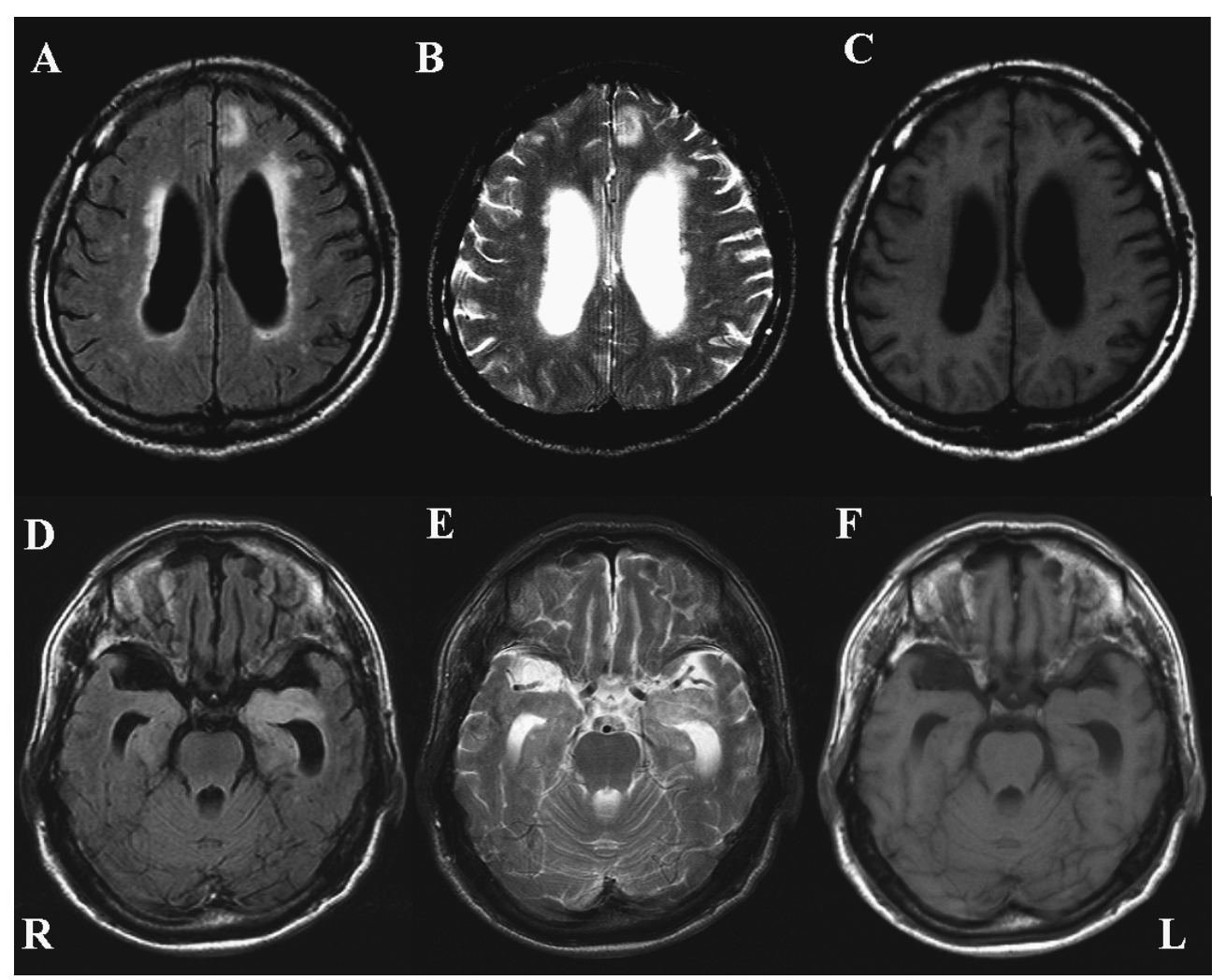

Figure 1. Brain MRI of our patient. Cortical and subcortical high signal intensity areas in both mesial temporal regions and the right frontal lobe are shown in fluid-attenuated inversion recovery (FLAIR) (A, D), T2WI (B, E). The abnormality is more intense in the left mesial temporal region. These regions are shown as hypointensity in a T1-weighted image $(C, F)$. The inferior horns of the lateral ventricle are dilated due to atrophy of the mesial temporal regions. Deep white matter changes are very subtle. There is no leptomeningeal thickening.

as follows: there was an elevation of serum TPHA to 80,220 $\mathrm{U} / \mathrm{mL}$ (normal range $<80 \mathrm{U} / \mathrm{mL}$ ), IgG-FTA-ABS was positive, whereas IgM-FTA-ABS was negative. A serum test for antibodies against human immunodeficiency virus (HIV-1 and HIV-2) was negative. His cerebrospinal fluid (CSF) was clear, with 7 polynuclear cells/ $\mu \mathrm{L}$ (normal range $<5$ polynuclear cells $/ \mu \mathrm{L}$ ), 14 monocytes $/ \mu \mathrm{L}$ (normal range $<5$ monocytes $/ \mu \mathrm{L}$ ), $67 \mathrm{mg} / \mathrm{dL}$ sugar (normal range $=50-80 \mathrm{mg} / \mathrm{dL}$ ), and $55 \mathrm{mg} / \mathrm{dL}$ protein (normal range $=15-40 \mathrm{mg} / \mathrm{dL}$ ). The level of herpes simplex virus (HSV) IgG in the CSF was 0.2 GI (normal range $<0.1 \mathrm{GI}$ ); that of HSV IgM was under 0.5 MI (normal range $<0.5 \mathrm{MI}$ ). Polymerase chain reactions for HSV-1 and HSV-2 DNA were negative. CSF bacterial and fungal cultures were also negative. His CSF was reactive for TPHA, at a level of 4,332 U/mL (normal range $<10 \mathrm{U} / \mathrm{mL}$ ). CT demonstrated atrophy of the temporal lobes. MRI showed an abnormal signal region within both mesial temporal regions and the right frontal lobe without enhancement (Fig. 1). The abnormality was more intense in the left mesial region. The inferior horns of the lateral ventricle were dilated due to atrophy of the mesial temporal regions. There was no leptomeningeal enhancement. Diffusion-weighted images revealed high signal and an ADC map showed low signal in the same region.

The patient was diagnosed as having neurosyphilis, as this patient fulfilled Hooshmand's criteria (2), and treatment for neurosyphilis was started. He received a 14-day course of penicillin G (2.4 million units/day) and probenecid (2 g/ day). His psychiatric symptoms gradually recovered, but two months after the administration of penicillin, there was still minor impairment of intellect and memory. His MMSE score after two months of treatment was 23/30. The levels of TPHA improved in both serum (TPHA 45,624 U/mL) and CSF (TPHA 2,967 U/mL). MRI showed a regression of the abnormal signal intensity in the temporal lobes.

\section{Discussion}

Bilateral mesiotemporal T2WI hyperintensity on MRI and a subacute onset of memory disturbance and psychiatric abnormalities are characteristic of paraneoplastic limbic encephalitis (3), but are not specific to it. It should be realized that other neurological disorders, such as herpetic and nonherpetic viral encephalitis, malignant lymphoma, and HIV encephalopathy, also involve limbic structures symmetrically. Thus, before starting therapy, it is necessary to make a precise differential diagnosis of bilateral mesiotemporal hyperintensity on T2WI. As reported here, it is clinically important to note that bilateral mesiotemporal hyperintensity on $\mathrm{T}$ 2 WI can occasionally be observed in patients with neuro- 
Table 1. Clinical Characteristics of Hitherto Reported Patients with Neurosyphilis-induced Hyperintensity on T2WI in the Medial Temporal Lobes

\begin{tabular}{|c|c|c|c|c|}
\hline Patient & Age/sex & Clinical Symptoms & Duration $^{*}$ & Pupils \\
\hline 1 & $34 / \mathrm{man}$ & altered mental status, drooling & 3 days & n.d. \\
\hline 2 & $51 / \mathrm{man}$ & disorientation, amnesia & acute onset & n.d. \\
\hline 3 & $50 /$ man & increasing memory difficulties & 3 months & normal \\
\hline 4 & $55 / \mathrm{man}$ & confusion & acute onset & normal \\
\hline 5 & $41 / \operatorname{man}$ & memory disturbance & 5 months & n.d. \\
\hline 6 & $62 /$ man & aphasia & acute onset & n.d. \\
\hline 7 & $37 / \mathrm{man}$ & cognitive decline, tinnitus, deafness & 2 years & sluggish pupilary response \\
\hline 8 & $47 /$ man & behavioral disturbance, personality change, & 2 years & n.d. \\
\hline & & memory impairment & & \\
\hline 9 & $48 /$ man & dreamy state with automatisms & 9 hours & n.d. \\
\hline 10 & $34 / \mathrm{man}$ & epileptic seizure & acute onset & n.d. \\
\hline 11 & $73 /$ man & $\begin{array}{l}\text { limb weakness, } \\
\text { disequilibrium, confusion }\end{array}$ & 10 days & n.d. \\
\hline 12 & $52 /$ man & emotional disturbance & 9 months & normal \\
\hline 13 & $41 /$ man & $\begin{array}{l}\text { a presumptive partial complex seizure, } \\
\text { weight loss }\end{array}$ & 6 months & n.d. \\
\hline Our case & $51 /$ man & personality changes & 10 months & dilated tonic pupils \\
\hline
\end{tabular}

Table continues on the next page.

syphilis.

Although it is by no means easy to make a diagnosis of atypical neurosyphilis like that in the patient, one available diagnostic key might be the pupillary abnormalities. While the Argyll Robertson pupil is well known as a pupillary abnormality associated with neurosyphilis, we should also realize that various other pupillary findings are actually not uncommon. Tonic pupil is initially unilateral and accompanied by accommodative paresis, and has been noted infrequently with neurosyphilis (4-6). Syphilitic patients are likely to have bilateral tonic pupils. Thus, patients with bilateral tonic pupils should be screened for syphilis.

Currently, the pathogenic background underlying mesial temporal hyperintensity on T2WI in neurosyphilis remains uncertain. Unfortunately, there has been no pathological study on mesial temporal hyperintensity on T2WI in neurosyphilis patients.

In the literature, there have been a total of thirteen neurosyphilitic patients who showed a similar MRI finding in their medial temporal lobes (Table 1) (7-19). As shown in Table 1, all of them were men. The duration until the illness became symptomatic is generally short, at most two years. The prognosis is generally good in patients with syphilis- induced mesial temporal hyperintensity on T2WI. The clinical symptoms shown in Table 1 are usually found during the late stage of syphilis infection, but the prognosis in patients with mesial temporal hyperintensity on T2WI seems to be better than in those with late-stage syphilis. Mesial temporal hyperintensity on T2WI might occur during an earlier stage, and the etiology might be not only the infection itself, but also unusual causes, such as allergic reactions and autoimmune processes.

The location of the lesion varied among patients; in five of them, bilateral temporal lobes were involved, while in the others, a unilateral temporal lobe was involved. In addition to the temporal lobe, the frontal lobe was also involved in five patients. Diffusion MRI was studied in five of them, and showed a hyperintensity similar to the T2WIs in all of them. MRI contrast enhancement was studied in eight patients; leptomeningeal enhancement was seen in one patient, and enhancement in other areas, such as the medial temporal region, temporal lobe, insula and fronto-parietal area, was seen in four patients. In all reported patients, the medial temporal lobe lesions improved after successful treatment of neurosyphilis.

In the present patient the duration from the time the ill- 


\begin{tabular}{|c|c|c|c|}
\hline Patient & CSF findings & Outcome & Reference \\
\hline 1 & $26 \mathrm{WBC} / \mu \mathrm{L}$ (Lym 91\%), Pro $94 \mathrm{mg} / \mathrm{dL}$, Glu $58 \mathrm{mg} / \mathrm{dL}$ & gradual recovery & 7) \\
\hline 2 & $26 \mathrm{WBC} / \mu \mathrm{L}$ (Lym 80\%), Pro $46 \mathrm{mg} / \mathrm{dL}$, Glu normal level & back to work & 8) \\
\hline 3 & $19 \mathrm{WBC} / \mu \mathrm{L}$ (Lym 93\%), Pro $87 \mathrm{mg} / \mathrm{dL}$, Glu $45 \mathrm{mg} / \mathrm{dL}$ & significant improvement & 9) \\
\hline 4 & $79 \mathrm{WBC} / \mu \mathrm{L}$ (Lym 93\%), Pro $71 \mathrm{mg} / \mathrm{dL}$, Glu $65 \mathrm{mg} / \mathrm{dL}$ & significant improvement & 10) \\
\hline 5 & 122 Cells $/ \mu \mathrm{L}$, Pro $145 \mathrm{mg} / \mathrm{dL}$, Glu $62 \mathrm{mg} / \mathrm{dL}$ & mild improvement & 11) \\
\hline 6 & $5 \mathrm{Lym} / \mu \mathrm{L}$ & only mild anomia & 12) \\
\hline 7 & $34 \mathrm{WBC} / \mu \mathrm{L}$ (Lym 88\%), Pro $143 \mathrm{mg} / \mathrm{dL}$, Glu $49 \mathrm{mg} / \mathrm{dL}$ & partially recovered, but unable to work & 13) \\
\hline 8 & 5 Mononuclear cells $/ \mu \mathrm{L}$, Pro $64 \mathrm{mg} / \mathrm{dL}$, Glu $59 \mathrm{mg} / \mathrm{dL}$ & improvement & 14) \\
\hline 9 & 12 lymphocytes $/ \mu \mathrm{L}$, Pro $63 \mathrm{mg} / \mathrm{dL}$, Glu normal level & n.d. & 15) \\
\hline 10 & 4 Cells $/ \mu \mathrm{L}$, Pro $953 \mathrm{mg} / \mathrm{dL}$ & subsequently improved & 16) \\
\hline 11 & $14 \mathrm{WBC} / \mu \mathrm{L}$ (Mono 94\%), Pro $89 \mathrm{mg} / \mathrm{dL}$, Glu $64 \mathrm{mg} / \mathrm{dL}$ & rapid neurological improvement & 17) \\
\hline 12 & 8 cells $/ \mu \mathrm{L}$, Pro $60 \mathrm{mg} / \mathrm{dL}$, Glu $67 \mathrm{mg} / \mathrm{dL}$ & good recovery & 18) \\
\hline 13 & 12 nucleated cells $/ \mu \mathrm{L}$ (Lym 75\%), Pro $123 \mathrm{mg} / \mathrm{dL}$, Glu $60 \mathrm{mg} / \mathrm{dL}$ & n.d. & 19) \\
\hline Our case & 7 polynuclear cells/ $\mu \mathrm{L}$, Pro $55 \mathrm{mg} / \mathrm{dL}$, Glu $67 \mathrm{mg} / \mathrm{dL}$ & slight improvement & \\
\hline
\end{tabular}

ness became symptomatic was relatively longer than that of the hitherto reported patients, resulting in a delay in the start of therapeutic intervention. This may be the reason for the brain atrophy and the incomplete recovery of the present patient. Since adequate early treatment may prevent further progression of the disease, and also allow marked recovery, early and precise diagnosis is strongly desired. To this end, pupillary findings could provide a hint regarding the correct diagnosis. Unfortunately, there have been few descriptions of pupils in the hitherto reported cases.

We want to stress that syphilis is still a cause of cognitive deterioration in our era, and we should not miss it. We hope that our experience reinforces the importance of considering neurosyphilis in patients with suspected paraneoplastic limbic encephalitis that have mesial temporal hyperintensity on T2WI.

\section{References}

1. Brightbill TC, Ihmeidan IH, Post MJ, Berger JR, Katz DA. Neurosyphilis in HIV-positive and HIV-negative patients: neuroimaging findings. Am J Neuroradiol 16: 703-711, 1995.

2. Hooshmand H, Escobar MR, Koph SW. Neurosyphilis. A study of 241 patients. JAMA 219: 726-729, 1972.

3. Mori M, Ogawara K, Hattori T. Paraneoplastic limbic encephalitis. Nippon Rinsho 62 Suppl : 335-339, 2004 (in Japanese).

4. Fletcher WA, Sharpe JA. Tonic pupils in neurosyphilis. Neurology 36: 188-192, 1986.

5. Englestein ES, Ruderman MI, Troiano RA, Digiovanni VJ. Dilated tonic pupils in neurosyphilis. J Neurol Neurosurg Psychiatr 49: 1455-1457, 1986.

6. Yasaki S, Ohshima J, Yonekura J, Takahashi Y, Someya K. A case of early syphilis presenting general paresis-like symptoms and bilateral tonic pupils. Clin Neurol 32: 994-999, 1992.

7. Angus F, Maysuria H, Bryan CS. Neurosyphilis mimicking herpes simplex encephalitis. J S C Med Assoc 94: 315-317, 1998.

8. Denays R, Collier A, Rubinstein M, Atsama P. A 51-year-old woman with disorientation and amnesia: case report. Lancet 354: 1786, 1999.

9. Bash S, Hathout GM, Cohen S. Mesiotemporal T2-weighted hy- perintensity: Neurosyphilis mimicking Herpes encephalitis. Am J Neuroradiol 22: 314-316, 2001.

10. Szilak I, Marty F, Helft J, Soeiro R. Neurosyphilis presenting as herpes simplex encephalitis. Clin Infect Dis 32: 1108-1109, 2001.

11. Fujimoto $H$, Imaizumi $T$, Nishimura $Y$, et al. Neurosyphilis showing transient global amnesia-like attacks and magnetic resonance imaging abnormalities mainly in the limbic system. Intern Med 40: 439-442, 2001.

12. Lauria G, Erbetta A, Pareyson D, Sghirlanzoni A. Parenchymatous neurosyphilis. Neurol Sci 22: 281-282, 2001.

13. Silberstein P, Lawrence R, Pryor D, Shnier R. A case of neurosyphilis with a florid Jarisch-Herxheimer reaction. J Clin Neurosci 9: 689-690, 2002.

14. Berbel-Garcia A, Porta-Etessam J, Martinez-Salio A, et al. Magnetic resonance image-reversible findings in a patient with general paresis. Sex Transm Dis 31: 350-352, 2004.

15. Marano E, Briganti F, Tortora F, et al. Neurosyphilis with complex partial status epilepticus and mesiotemporal MRI abnormalities mimicking herpes simplex encephalitis. J Neurol Neurosurg Psychiatr 75: 833, 2004.

16. Scheid R, Voltz R, Vetter T, Sabri O, Cramon DYV. Neurosyphilis 
Inter Med 47: 1813-1817, 2008 DOI: 10.2169/internalmedicine.47.0983

and paraneoplastic limbic encephalitis: important differential diagnosis. J Neurol 252: 1129-1132, 2005.

17. Santos AV, Matias S, Saraiva P, Goulao A. Differential diagnosis of mesiotemporal lesions: case report of neurosyphilis. Neuroradiology 47: 664-667, 2005.

18. Chen C, Chiang H, Chen P, Hsieh PF, Lee Y, Chang MH. General paresis with reversible mesial temporal $\mathrm{T} 2$-weighted hyperintensity on magnetic resonance image: a case report. Acta Neurol Taiwan 14: 208-212, 2005.

19. Fadil H, Gonzalez-Toledo E, Kelley BJ, Kelly RE. Neuroimaging findings in neurosyphilis. J Neuroimaging 16: 286-289, 2006.

\footnotetext{
(C) 2008 The Japanese Society of Internal Medicine http://www.naika.or.jp/imindex.html
} 